\title{
Association between short sleep duration and overweight/obesity among middle-school students: a cross-sectional study in Fuzhou, China
}

Guobo Li

Fujian Medical University

Shichao Wei

Fujian Provincial Hospital

Fuhao Zheng

Fujian Provincial Hospital

Xingyan Xu

Fujian Medical University

\section{Yingying Cai}

Fujian Medical University

Siying Wu ( $\nabla$ fmuwsy@163.com )

the Key Laboratory of Environment and Health among Universities and Colleges in Fujian; Fujian

Medical University

Research article

Keywords: Short sleep duration, Overweight, Obesity, Adolescents, Association

Posted Date: January 12th, 2021

DOl: https://doi.org/10.21203/rs.3.rs-30129/v4

License: (1) (1) This work is licensed under a Creative Commons Attribution 4.0 International License.

Read Full License 


\section{Abstract}

Background: This study was designed to investigate the prevalence of short sleep duration and its association with overweight or obesity in adolescents from middle school in Fuzhou, China.

Methods: A total of 13,063 students (male: 6,500; female: 6,553) from 18 different schools in Fuzhou city were included in this study. Questionnaires focusing on short sleep duration and overweight or obesity related factors were collected. The sleep duration was self-reported by the subjects. The body weight and height were measured by the qualified personnel. Logistic regression analysis was used to evaluate the effects of short sleep duration on overweight or obesity in school students.

Results: The overall rates of overweight and obesity were $12.1 \%$ and $7.1 \%$, respectively. The prevalence of short sleep duration among students was $82.8 \%$. The majority of high school students (92.5\%) showed a short sleep duration. Compared with male children with a sleep duration of 8-10 $\mathrm{h}$ per day, the odds ratios (ORs) of overweight/obesity for those with a sleep duration of less than $6 \mathrm{~h}$ or $6-8 \mathrm{~h}$ per day were 1.60 (1.22-2.09) and 1.07 (0.90-1.29) after adjusting social and demographic status, mental health and lifestyle factors. The homologous ORs of female children were 1.45 (1.04-2.04) and 1.11(0.85-1.45), respectively.

Conclusions: A large number of adolescents suffered from short sleep duration. Short sleep duration is associated with a higher OR of overweight/obesity in middle-school children, especially in the male adolescences.

\section{Background}

Overweight and obesity, with an increased trend in the past few decades, have been considered a threat to the public health worldwide. In a recent survey, about 711.4 million individuals were diagnosed with obesity, among which 107.7 million were children [1]. Meanwhile, a large proportion of adolescents (19.4\%) aged 7-18 yrs presented overweight and obesity in a national survey [2]. In China mainland, the number of obese children is very huge because of alternations in the diet compared with the previous decades [1]. Fuzhou is the capital city of Fujian Province localized in the southeast of China. In 2010, Lin et al reported the body development of the students in middle school in Fuzhou city [3], however, few studies focused on the incidence of overweight/obesity and the relationship between overweight/obesity and the sleep duration in these students.

Obesity is considered to be associated with the genetic and environmental factors [4, 5]. Nowadays, more and more attention has been paid to sleep duration among the individuals with obesity [6]. Short sleep duration is regarded to be related to increased risk of obesity, injuries, behavior problems, attention-deficit disorder, poor academic performance and psychological problems in students [7-9]. In adulthood, short sleep duration is a risk factor of cardiovascular diseases [10]. Until now, short sleep duration has been acknowledged to affect metabolism, endocrine function and immune systems [11]. However, there are still some controversies on the relationship between short sleep duration and overweight or obesity. Some 
studies proposed a U-shaped [12,13] or linear inverse correlation [14] between sleep duration and obesity, however, some studies proposed no correlation between them $[15,16]$. Meanwhile, the association between short sleep duration and the overweight/obesity was somehow affected by sex [17], in which the sex was considered a specific trait for short sleep duration in these with overweigh/obesity $[18,19]$. In this study, we aimed to investigate the prevalence of short sleep duration among students in Fuzhou. In addition, we explored the relationship between short sleep duration and overweight or obesity.

\section{Methods}

\section{Survey design}

Cluster random sampling method was utilized in our survey. Firstly, five representative cities and four rural areas were selected from Fuzhou City. Secondly, the adolescents from two selected middle schools were enrolled randomly from the selected counties. Thirdly, all students in the selected classes were invited to participate in the study by the qualified teachers in their school after informing about the potential benefits and risks by our staff. All the subjects were invited to participate in this study at their wills, and those not willing to participate in this survey were excluded. A total of 15,025 students from 18 different schools were invited, and finally 14,499 students (96.5\%) participated in the survey. After exclusion of subjects with missing key variables (e.g. sex, height, weight and sleep duration), 13,063 eligible subjects (male: 6,500; female: 6,553) were included in the final analyses. Existing investigation was modeled from the questionnaire including the Youth Risk Behavior Survey, performed by the Centers for Disease Control and Prevention [20], and the international Global School-based Student Health Survey conducted with the support of WHO [21]. Questionnaires distributed to the respondents included the demographic characteristics (e.g. age and sex), athletic activity, screen-time, nutrient supplements, as well as sleep and mental health (e.g. sadness, annoyance and loneliness). This survey was conducted between May and June in 2019. The age of the youngest participants was 12-year old. Written parental consent was obtained on behalf of participants below the age of 16 . The study was approved by the Ethical Committee of Fujian Medical University (approval No. 2019-117).

The sample size was calculated using the following formula: $N=\operatorname{deff} \times \mu^{2} \times P \times(1-P) / d^{2}$. In addition, the $95 \%$ confidential interval $(95 \% \mathrm{Cl})(2$-sided for $\mu=1.96)$ was determined, and the measure of probability $(P)$ was the obese rate (8.6\%) of China [2]. The design effect (deff) value was set to 2 and the relative error ( $d$ value) was $d=r \times 0.01(r=15 \%)$. On this basis, the sample size was 2,680 for each stratum. After taking 4 strata (i.e. boy and girl, urban and rural area) and an assumed potential non-response rate of $10 \%$ into consideration, the final sample size was 11,929 .

\section{Definition of the variables}

The key schools were defined as these supported by the local government and the education bureau, with more high quality teachers and students. The ordinary schools were those supported less by the local government and the education bureau, and lower in the quality of the teachers and students compared 
with the key schools. The environment for the learning and capacity of the key schools was much better than that of the ordinary schools.

\section{Overweight and obesity screening}

The body weight and height of each subject were measured by the qualified staff annually in the routine physical examination. Body mass index (BMI) was the result of measured weight ( $\mathrm{kg}$ ) divided by the square of height in meters. The diagnostic criteria for overweight and obesity among adolescents were conducted based on the guidelines proposed by the Chinese Working Group on Obesity for Children (WGOC) [22]. Overweight was defined as increase of one standard deviation (SD) of BMI compared with the normal children of the same sex at the same age, and obesity was defined as increase of two standard deviations (SDs) of BMI. The disease history was inquired by the staff, followed by physical examination to exclude the secondary obesity induced by severe diseases, endocrine or metabolic disorders.

\section{Sleep duration}

Sleep duration was calculated by self-administered questionnaires by recalling the average time of falling asleep and getting up in the preceding 7 days. The average time of using electronic products each day was also self-administered. Short sleep duration was defined as a sleep duration less than 8 hrs a day for teenagers aged $\geq 13$ according to the recommendation of American Academy of Sleep Medicine (AASM) [23]. Sleep duration was subdivided into 3 groups: " $<6 h$ ", "6-8 $h$ ", and "8-10 h", as a categorical variable in the multivariable logistic regression.

\section{Co-variates}

The questionnaire also investigated other factors related to obesity, including the sex and age, days for consuming breakfast and night snack, physical activity, homework time, high-energy snacks, fast food intake and nutrient supplements.

\section{Statistical analysis}

SPSS 26.0 software was used for the statistical analysis. Continuous variables were described by mean $\pm S D$. Chi square test was utilized to analyze the differences in overweight and obese rates of different groups. For the analysis of the correlation between short sleep duration and the overweight or obesity, the generalized linear mixed model was utilized with the school and district as the variables for the random effects and other factors as the fixed effect variables. Adjusted ORs and $95 \% \mathrm{Cl}$ were evaluated through three logistic regression models. $P<0.05$ was considered to statistical significance. In this study, obesity and overweight was classified as one group based on the following aspects: (i) The sample size for obesity was small, which may hamper the confidence of the data. (ii) The effects of short sleep duration on overweight and obesity were similar. There was a relationship between sleep duration and overweight. Short sleep duration may lead to overweight in children [24, 25]. Besides, short sleep duration may increase the risk of obesity in children [26-28]. Meanwhile, many studies classified the 
overweight and obesity as the same group, in order to analyze the effects of sleep duration on overweight and obesity [13, 29-31].

In order to further validate whether the sex would modulate the effects of overweight on the short sleep duration, we analyzed the correlation between short sleep duration and overweight/obesity among the male and female adolescence. In the Logistics regression analysis, no additional variable was given in Model 0 . The Model 1 of total subject involved adjustment for sex, age. For the Model 1 of male and female, we adjusted sex, region, and types of school. For the Model 2 of the three aspects, we additionally adjusted for utility of electronic product daily during school or in bedroom, smoking at home, strenuous physical activity, moderate physical activity, days of consuming breakfast and night snack per week, having fried food or pastry in the past 12 months, taking nutrient supplements in the past 12 months. Besides, they were further adjusted for feeling annoy, sad or lonely in the Model 3 of the three aspects.

\section{Results}

\section{Respondent characteristics}

Finally, 13,063 subjects (male: 6,500; female: 6,553) were included in this study. The respondents with short sleep duration had longer screen-time than that of the counterparts with short sleep duration, $(P<0.001$, Table 1). Meanwhile, compared with those with long sleep duration, these with a short sleep duration were less likely to participate in physical activity $(P<0.001)$ or have breakfast $(P<0.001)$. Instead, short sleep duration was significantly linked to consuming night snack $(P<0.001)$, irritation $(P<0.001)$, sad $(P<0.001)$ and lonely $(P<0.001)$.

Table 1 Sleep duration of middle school students in Fuzhou, China 


\begin{tabular}{|c|c|c|c|c|c|c|}
\hline aracteristics & $\begin{array}{l}\text { Total } \\
(\mathrm{n}=13063)\end{array}$ & $\begin{array}{l}<6 \mathrm{~h} \\
(\mathrm{n}=1762)\end{array}$ & $\begin{array}{l}6-8 \mathrm{~h} \\
(\mathrm{n}=9051)\end{array}$ & $\begin{array}{l}8-10 \mathrm{~h} \\
(\mathrm{n}=2250)\end{array}$ & $\mathrm{F} / \mathrm{C}^{2}$ & $P$ value \\
\hline э (years) & $14.44 \pm 1.64$ & $14.94 \pm 1.65$ & $14.53 \pm 1.64$ & $13.66 \pm 1.36$ & 369.68 & $<0.001$ \\
\hline nder & & & & & 103.26 & $<0.001$ \\
\hline ioys & $6520(49.9)$ & $802(45.5)$ & $4381(48.4)$ & $1337(59.4)$ & & \\
\hline iirls & $6543(50.1)$ & $960(50.1)$ & $4670(51.6)$ & $913(40.6)$ & & \\
\hline ses of school & & & & & 3.86 & 0.145 \\
\hline ey school & 7817(59.8) & $1092(62.0)$ & 5386(59.5) & $1339(59.5)$ & & \\
\hline Irdinary school & $5246(40.2)$ & $670(38.0)$ & $3665(40.5)$ & $911(40.5)$ & & \\
\hline tas & & & & & 57.41 & $<0.001$ \\
\hline Jrban & $5924(45.3)$ & $860(48.8)$ & $3910(43.2)$ & $1154(51.3)$ & & \\
\hline 'ural & $7139(54.7)$ & $902(51.2)$ & $5141(56.8)$ & 1096(48.7) & & \\
\hline een time per & & & & & 210.20 & $<0.001$ \\
\hline \multicolumn{7}{|l|}{ ing school } \\
\hline 30minute & $5386(41.2)$ & $596(33.8)$ & $3659(40.4)$ & $1131(50.3)$ & & \\
\hline $0-60$ minute & $3949(30.2)$ & $469(26.6)$ & 2814(31.1) & $666(29.6)$ & & \\
\hline :60minute & $3728(28.5)$ & 697(18.7) & $2578(28.5)$ & $453(20.1)$ & & \\
\hline $\begin{array}{l}\text { ing electronic } \\
\text { iducts } \\
\text { Jedroom }\end{array}$ & $8422(64.5)$ & $1254(71.2)$ & $5898(65.2)$ & $1270(56.4)$ & 99.70 & $<0.001$ \\
\hline $\begin{array}{l}\text { neone smoking } \\
\text { nome }\end{array}$ & 7163(55.4) & 1015(58.2) & 4954(55.2) & 1194(53.6) & 8.69 & 0.013 \\
\hline $\begin{array}{l}\text { ing strenuous } \\
\text { ircise } \\
\text { spare time }\end{array}$ & $8362(65.4)$ & $1032(59.8)$ & $5749(65.0)$ & $1581(71.8)$ & 64.95 & $<0.001$ \\
\hline $\begin{array}{l}\text { at } \\
\text { derate intensity } \\
\text { spare time }\end{array}$ & 7057(55.8) & $837(49.0)$ & 4896(55.8) & $1324(60.9)$ & 55.43 & $<0.001$ \\
\hline $\begin{array}{l}\text { ys for consuming } \\
\text { :akfast }\end{array}$ & $6.13 \pm 1.56$ & $5.52 \pm 1.99$ & $6.17 \pm 1.48$ & $6.40 \pm 1.36$ & 163.74 & $<0.001$ \\
\hline $\begin{array}{l}\text { ys } \\
\text { tsuming } \\
\text { ht snack }\end{array}$ & $2.10 \pm 2.34$ & $2.39 \pm 2.51$ & $2.09 \pm 2.29$ & $1.91 \pm 2.35$ & 19.44 & $<0.001$ \\
\hline $\begin{array}{l}\text { ving fried food } \\
\text { en in the past } 12 \\
\text { nths }\end{array}$ & 7468(70.9) & $950(70.2)$ & $5279(71.6)$ & $1239(68.7)$ & 6.17 & 0.046 \\
\hline $\begin{array}{l}\text { ving pastry } \\
\text { en in the past } 12 \\
\text { nths }\end{array}$ & $8342(80.6)$ & 1035(78.5) & $5880(81.1)$ & $1427(80.3)$ & 5.16 & 0.076 \\
\hline $\begin{array}{l}\text { trition } \\
\text { splements in the }\end{array}$ & $4982(51.3)$ & $612(49.6)$ & 3518(51.6) & $852(51.7)$ & 1.64 & 0.441 \\
\hline
\end{tabular}


it 12 months

:quency of

ling lonely

Jever

ometimes

$4760(36.7) \quad 443(25.3)$

$3255(36.2)$

$1062(47.7)$

lways

6397(49.4) 888(50.8)

4584(51.0)

925(41.5)

1803(13.9) 417(23.9)

1145(12.7)

$241(10.8)$

:quency of

ling sad

Jever

ometimes

lways

:quency of

ling irritated

Jever

ometimes

4795(37.0) $489(28.0)$

3291 (36.7)

$1015(45.5)$

6877(53.1) 945(54.1)

4919(54.8)

1013(45.5)

1283(9.9) 314(18.0)

$768(8.6)$

$201(9.0)$

$245.29<0.001$

$316.78<0.001$

lways

2084(16.3)

207(12.0)

$1281(14.4)$

$596(27.1)$

$8771(68.5) \quad 1054(61.1)$

6353(71.5)

$1364(62.1)$

1946(15.2) 463(26.9)

$1246(14.0)$

237(10.8)

\section{Overweight and obesity}

The prevalence of overweight and obesity were $12.1 \%$ and $7.1 \%$, respectively (Table 2 ). They were statistically differences different in the rate of obesity and overweight among various regions $(P<0.001)$. No statistical differences were noticed in the rate of obesity and overweight between the students in the key schools and ordinary schools $(P=0.566)$. The prevalence of obesity rate of among the male children was significantly higher than that of female counterparts $(P<0.001)$.

Table 2 Prevalence of overweight and obesity among different groups [n(\%)]

\begin{tabular}{|c|c|c|c|c|c|c|c|}
\hline Characteristics & Normal & $\begin{array}{c}\text { Overweight/ } \\
\text { obesity }\end{array}$ & Overweight & Obesity & Total & $c^{2}$ & $P$ value \\
\hline Gender & & & & & & 365.53 & $<0.001$ \\
\hline Boys & $4849(74.4)$ & $1671(25.6)$ & $1106(17.0)$ & $565(8.7)$ & 6520 & & \\
\hline Girls & $5704(87.2)$ & 839(12.8) & $473(7.2)$ & $366(5.6)$ & 6543 & & \\
\hline Area & & & & & & 48.51 & $<0.001$ \\
\hline Urban & $4635(78.2)$ & $1289(21.8)$ & $789(13.3)$ & $500(8.4)$ & 5924 & & \\
\hline Rural & $5918(82.9)$ & $1221(17.1)$ & $790(11.1)$ & $431(6.0)$ & 7139 & & \\
\hline Age (y) & & & & & & 94.38 & $<0.001$ \\
\hline$\leq 13$ & $3866(78.3)$ & $1071(21.7)$ & $592(12.0)$ & $479(9.7)$ & 4937 & & \\
\hline $14-15$ & $3133(81.3)$ & $721(18.7)$ & $470(12.2)$ & $251(6.5)$ & 3854 & & \\
\hline$\geq 16$ & $3559(83.3)$ & $713(16.7)$ & $517(12.1)$ & $196(4.6)$ & 4272 & & \\
\hline Types of School & & & & & & 1.14 & 0.566 \\
\hline Key school & $6335(81.0))$ & $1482(19.0)$ & $939(12.0)$ & $543(6.9)$ & 7817 & & \\
\hline Ordinary school & $4218(80.4))$ & 1028(19.6) & $640(12.2)$ & $388(7.4)$ & 5246 & & \\
\hline Total & $10553(80.8)$ & $2510(19.2)$ & 1579(12.1) & $931(7.1)$ & 13063 & & \\
\hline
\end{tabular}




\section{Short sleep duration}

The total prevalence of short sleep duration was $82.8 \%$. The prevalence of short sleep duration among the female children was significantly higher than that in male counterparts $(86.0 \%$ vs. $79.5 \% P<0.001)$. There were statistical differences among the prevalence of short sleep duration in the students aged $\leq 13 \mathrm{yrs}$ (67.7\%), those aged $14-15 \mathrm{yrs}(77.8 \%)$ and those aged $\geq 16 \mathrm{yrs}(92.5 \%, P<0.001)$. The prevalence of short sleep duration in the students lived in the urban was significantly lower than those lived in the rural areas $(80.5 \%$ vs. $84.6 \%, P<0.001)$. No statistical difference was noticed in the prevalence of short sleep duration in the students of the key schools and ordinary schools ( $82.9 \%$ vs. $82.6 \%, P=0.726)$.

\section{Relationship between sleep duration and overweight/obesity}

As shown in Model 1, compared with all the subjects and male children who slept 8-10h per day, those who slept for less than $6 \mathrm{hrs}$ a day showed a higher possibility of overweight/obesity after adjusting socio-demographic status [OR=1.32 (95\% Cl: 1.12-1.56) and 1.23 (95\% Cl: 1.00-1.51)] (Table 3 and Table 4). After additionally adjusting life-style factors in Model 2 , all the subjects and male children who slept for less than 6 hrs a day showed a significantly higher association for overweight/obesity in comparison with the reference group [OR=1.55 (95\%Cl: 1.27-1.90) and 1.60 (95\% Cl: 1.23-2.07)]. The Ors were 1.53 (1.24-1.88) and 1.60 (1.22-2.09), after further adjustment for mental health such as feeling irritation, sad or lonely. Similarly, there were significant differences among the female children. The homologous ORs for female children were 1.44 (1.10-1.89) in Model 1, 1.51 (1.08-2.11) in Model 2 and 1.45 (1.04-2.04) in Model 3 , respectively. Nevertheless, the lower $\mathrm{Cl}$ was very close to significance.

Table 3 Odds ratios of overall overweight/obese based on sleep duration

\begin{tabular}{llll}
\hline Characteristics & $<6 \mathrm{~h}$ & $6-8 \mathrm{~h}$ & $8-10 \mathrm{~h}$ \\
\hline Total $(\mathrm{n})$ & 1762 & 9051 & 2250 \\
Overweight/obese (n) 376 & 1669 & 465 \\
Model 0 & $1.07(0.92-1.26)$ & $0.91(0.81-1.02) 1.00$ \\
Model 1 & $1.32(1.12-1.56)^{* *}$ & $1.05(0.93-1.89) 1.00$ \\
Model 2 & $1.55(1.27-1.90)^{* *}$ & $1.09(0.94-1.27) 1.00$ \\
Model 3 & $1.53(1.24-1.88)^{* *}$ & $1.09(0.94-1.27) 1.00$ \\
\hline
\end{tabular}

Model 0, no additional variables

Model 1, adjustment for gender, age.

Model 2, additionally adjusted for whether using electronic product daily during school, electronics in bedroom, someone smoking at home, strenuous physical activity, moderate physical activity, days of consuming breakfast and night snack per week, having fried food or pastry in the past 12 months, having taken nutrient supplements in the past 12 months. Model 3, further adjusted for feeling annoy, sad or lonely

${ }^{*} P<0.05 ;{ }^{* *} P<0.01$ 
Table 4 Odds ratios of overweight/obese based on sleep duration in different gender

\begin{tabular}{llll}
\hline Characteristics & $<6 \mathrm{~h}$ & $6-8 \mathrm{~h}$ & $8-10 \mathrm{~h}$ \\
\hline Female & & & \\
Total (n) & 960 & 4670 & 913 \\
Overweight/obese (n) & 152 & 568 & 119 \\
$\quad$ Model 0 & $1.36(1.04-1.77)^{* *}$ & $0.98(0.79-1.22) 1.00$ \\
Model 1 & $1.44(1.10-1.89)^{* *}$ & $1.02(0.82-1.27) 1.00$ \\
Model 2 & $1.51(1.08-2.11)^{*}$ & $1.11(0.85-1.44) 1.00$ \\
Model 3 & $1.45(1.04-2.04)^{*}$ & $1.11(0.85-1.45) 1.00$ \\
Male & & & \\
Total (n) & 802 & 4381 & 1337 \\
Overweight/obese (n) & 224 & 1101 & 346 \\
Model 0 & $1.10(0.90-1.35)$ & $0.99(0.86-1.14) 1.00$ \\
Model 1 & $1.23(1.00-1.51)$ & $1.07(0.92-1.23) 1.00$ \\
Model 2 & $1.60(1.23-2.07)^{* *}$ & $1.07(0.80-1.29) 1.00$ \\
$\quad$ Model 3 & $1.60(1.22-2.09)^{* *}$ & $1.07(0.90-1.29) 1.00$ \\
\hline
\end{tabular}

Model 0, no addition variables

Model 1, adjustment for age.

Model 2, additionally adjusted for whether using electronic product daily during school, electronics in bedroom, someone smoking at home, strenuous physical activity, moderate physical activity, days of consuming breakfast and night snack per week, having fried food or pastry in the past 12 months, having taken nutrient supplements in the past 12 months. Model 3, further adjusted for feeling annoy, sad or lonely

${ }^{*} P<0.05 ;{ }^{* *} P<0.01$

\section{Discussion}

This study investigated the link between short sleep duration and overweight/obesity in adolescents of Fuzhou, China. After adjusting socio-demographic status, lifestyle factors, and mental health, there was a negative correlation between short sleep duration and overweight/obesity among male children.

The prevalence of overweight or obesity in our study was $19.2 \%$, which was higher than the national average [2]. Moreover, our findings demonstrated the differences among sex, age and region, which were similar with the Report on Childhood Obesity in China [32]. The prevalence of obesity showed decline with the elevation of the ages, which may be possibly related to physical development and attention to their appearances[33, 34].

The prevalence of obesity in male children was significantly higher than that of female children. In addition, the prevalence of short sleep duration in adolescents showed strike increase with age. About 
92.4\% of adolescents in high school showed a short sleep duration, which is possibly related to the study pressure, especially pressure from the college entrance examination.

Sleep deficiency was associated with increased prevalence of obesity[35]. Consistently, our study revealed that short sleep duration was negatively related to overweight/obesity. Meanwhile, it could be an independent risk factor for obesity[10,36,37]. One study provided causal evidence on the relationship between short sleep duration and weight gain in the population-level [38]. Moreover, Krietsch et al reported that there was a U-shaped correlation between those with short sleep duration and obesity only in the female children [39]. These differences may be related to the physiology between female and male adolescence.

To date, little is known about the relationship between sleep and obesity. Sleep duration was reported to involve in the regulation of cerebral function (e.g. appetite), which could lead to over-eating in an obesogenic environment [40]. The homeostatic control of appetite was achieved by complex interactions among numerous neuroendocrine hormones [41]. Many pivotal hormones (e.g. insulin, leptin, cortisol and ghrelin) [42] may involve in the association between sleep and obesity. Even after adjusting the BMI, sleep duration was negatively correlated with circulating leptin [43]. The leptin pathway could explain the key mechanism via modificatory effects [44]. Under some circumstances, the short sleep duration could lead to disruption of insulin, leptin, cortisol and ghrelin expression $[45,46]$. After a period of sleep loss, people could experient a $24 \%$ increase in hunger with largely whetting the appetite for high carbohydrate foods [45]. In our study, students with short sleep duration spent more time on night snack than those with adequate sleep, which may lead to weight gain. Fatigue caused by short sleep duration may result in reduction in the physical activity, which subsequently_promoted the weight gain $[47,48]$. In this study, adolescents with adequate sleep did more exercise of moderate-intensity than those with short sleep duration.

Circadian Locomotor Output Cycles Kaput (CLOCK) genes involved in regulation of diurnal rhythm, and their effects on neuroendocrine systems might have an impact on obesity [49]. The variants of CLOCK gene was related to sleep duration [50], calorie intake [51], metabolic syndrome [52], and obesity [53]. Meanwhile, methylation of $C L O C K$ gene was associated with carbohydrate intake, total energy intake, insulin resistance, and BMI [54]. REV-ERBa rs2071570 and rs2071427 were related to $\mathrm{BMI}$ and sleep duration in male children, which indicated that there was an association between the REV-ERBa gene and human obesity, especially in males [55]. In line with our findings, there was a negative correction between sleep duration and overweight/obesity among male children [56].

Obesity is related to biology and behavior, and the social context [57]. Social support from friends and awareness/internalization of thinness ideals were significantly related to odds of overweight/obesity in youth. Such association varied by age and sex, and persisted after control for intra-familial factors such as overall family support/function, diet and activity specific support [58]. A cross-sectional study on social risk factors for overweight and obesity in women in Zimbabwe showed that the key social factors associated with overweight and obesity were older age, wealthy and the use of hormonal contraception. 
Besides, a higher education and being Christian also increased the risk of obese and overweight, respectively [59]. Some home environment related factors may increase the incidence of overweight/obesity among children, such as sleeping too late that may lead to inadequate sleeping and increased opportunity for taking food in night [60]. Less daytime care by mothers and shorter sleep duration were associated with increased risk of overweight in the childhood [61].

A large and representative sample was included in the survey. Meanwhile, we analyzed a wide range of covariance to verify the relationships between sleep duration and overweight or obesity by adjusting potential confounding factors correlated with overweight or obesity. Nevertheless, there are some limitations in our study. First, causal inference will be limited in the cross-sectional design, although there are several theories supporting our findings. Second, the determination of sleep duration was reported by the students themselves, which was a limiting factor. Indeed, the facilities may contribute to the reduction of the errors, however, it was a challenge for the promotion of the facility as the sample size was too large. In the subsequent study, representative samples will be selected for the monitor of the sleep duration of the subjects including sleep quality. Third, the impact of prolonged sleep duration on overweight or obesity among adolescents was not investigated in our study, as we laid emphasis on the risk of overweight or obesity induced by short sleep duration in middle-school students. Then we will focus on the effects of long sleep duration on the overweight and obesity in the students. Fourth, the psychologic status of the subjects when self-reporting may lead to some bias of the results. In the followup study, qualified mental scales will be required to evaluate the psychologic status including depression and sorrow, which can correct the effects of psychologic variables on overweight and obesity.

\section{Conclusion}

Adolescents suffered from short sleep duration. Short sleep duration is associated with higher odds of overweight/obesity in middle-school children, especially in the male adolescences. Attention should be paid to ensure the sleeping duration of these students, in order to control the overweight and promote the healthy development. In future, further researches are required to investigate the relationship between sleep duration and specific hormones in adolescents, in order to explore the potential mechanisms of overweight or obesity.

\section{Abbreviations}

Body mass index (BMI)

Chinese Working Group on Obesity for Children (WGOC)

American Academy of Sleep Medicine (AASM)

Odds ratios

Circadian Locomotor Output Cycles Kaput (CLOCK) 


\section{Declarations}

\section{Ethics approval and consent to participate}

The study was approved by the Ethical Committee of Fujian Medical University.

\section{Consent for Publication}

Written parental consent was obtained on behalf of participants below the age of 16 .

\section{Availability of data and material}

All the data were available upon appropriate request.

\section{Competing interests}

The author(s) declare(s) that there is no conflict of interest regarding the publication of this paper.

\section{Funding}

This work was funded by Joint Funds for the Innovation of Science and Technology, Fujian Province (2018Y9089), Science and Technology Innovation Program of Fujian Provincial Maternal and Child Health Hospital (YCXM19-24), General Program of Fujian Medical University (2018QH1192) and Open Project of Fujian Key Laboratory of Environmental Factors and Cancer (GWSZD-201802). These funds showed no roles in the design of the study.

\section{Authors' contributions}

Designed and modified the manuscript: WSC and WSY; Designed the research and participated in the experimental design, coordinated and drafted the manuscript: $L G B, Z F H, X X Y, C Y Y$; Data collection, achievement interpretation and manuscript writing: LGB, ZFH, XXY, CYY; Analysed the data: LGB, XXY, CYY. All of the authors have given final approval of the version to be published.

\section{Acknowledgements}

Not applicable.

\section{References}

1. Afshin A, Forouzanfar MH, Reitsma MB, Sur P, Estep K, Lee A, Marczak L, Mokdad AH, Moradi-Lakeh $\mathrm{M}$, Naghavi $\mathrm{M}$ et al: Health Effects of Overweight and Obesity in 195 Countries over 25 Years. The New England journal of medicine 2017, 377(1):13-27.

2. Wang S, Dong YH, Wang ZH, Zou ZY, Ma J: [Trends in overweight and obesity among Chinese children of 7-18 years old during 1985-2014]. Zhonghua yu fang yi xue za zhi [Chinese journal of preventive medicine] 2017, 51(4):300-305. 
3. Xin L, Quan Z, Qiu Z: A Survey on the Growth and Development of primary and middle school students in Fuzhou [J]. Strait Journal of Preventive Medicine. 2014.

4. Wang L, Perez J, Heard-Costa N: Integrating genetic, transcriptional, and biological information provides insights into obesity. 2019, 43(3):457-467.

5. Vasanth Rao VRB, Candasamy M, Bhattamisra SK: Obesity an overview: Genetic conditions and recent developments in therapeutic interventions. Diabetes \& metabolic syndrome 2019, 13(3):21122120.

6. Celis-Morales C, Lyall DM, Guo Y, Steell L, Llanas D, Ward J, Mackay DF, Biello SM, Bailey ME, Pell JP et al: Sleep characteristics modify the association of genetic predisposition with obesity and anthropometric measurements in 119,679 UK Biobank participants. The American journal of clinical nutrition 2017, 105(4):980-990.

7. Allott EH, Hursting SD: Obesity and cancer: mechanistic insights from transdisciplinary studies. Endocrine-related cancer 2015, 22(6):R365-386.

8. Bragg F, Tang K, Guo Y, lona A, Du H, Holmes MV: Associations of General and Central Adiposity With Incident Diabetes in Chinese Men and Women. 2018, 41(3):494-502.

9. Lu Y, Hajifathalian K, Ezzati M, Woodward M, Rimm EB, Danaei G: Metabolic mediators of the effects of body-mass index, overweight, and obesity on coronary heart disease and stroke: a pooled analysis of 97 prospective cohorts with 1.8 million participants. Lancet (London, England) 2014, 383(9921):970-983.

10. Miller MA, Kruisbrink M, Wallace J, Ji C, Cappuccio FP: Sleep duration and incidence of obesity in infants, children, and adolescents: a systematic review and meta-analysis of prospective studies. Sleep 2018, 41(4).

11. Miller MA, Cappuccio FP: Biomarkers of cardiovascular risk in sleep-deprived people. Journal of human hypertension 2013, 27(10):583-588.

12. Danielsen YS, Pallesen S, Stormark KM, Nordhus IH, Bjorvatn B: The relationship between school day sleep duration and body mass index in Norwegian children (aged 10-12). International journal of pediatric obesity : IJPO : an official journal of the International Association for the Study of Obesity 2010, 5(3):214-220.

13. Wu J, Wu H, Wang J, Guo L, Deng X, Lu C: Associations between Sleep Duration and Overweight/Obesity: Results from 66,817 Chinese Adolescents. Scientific reports 2015, 5:16686.

14. Lytle LA, Pasch KE, Farbakhsh K: The relationship between sleep and weight in a sample of adolescents. Obesity (Silver Spring, Md) 2011, 19(2):324-331.

15. Calamaro CJ, Park S, Mason TB, Marcus CL, Weaver TE, Pack A, Ratcliffe SJ: Shortened sleep duration does not predict obesity in adolescents. Journal of sleep research 2010, 19(4):559-566.

16. Hassan F, Davis MM, Chervin RD: No independent association between insufficient sleep and childhood obesity in the National Survey of Children's Health. Journal of clinical sleep medicine: JCSM : official publication of the American Academy of Sleep Medicine 2011, 7(2):153-157. 
17. Cao M, Zhu Y, Li X, Chen Y, Ma J, Jing J: Gender-dependent association between sleep duration and overweight incidence in CHINESE school children: a national follow-up study. BMC public health 2018, 18(1):615.

18. Rosi A, Calestani MV, Parrino L, Milioli G, Palla L, Volta E, Brighenti F, Scazzina F: Weight Status Is Related with Gender and Sleep Duration but Not with Dietary Habits and Physical Activity in Primary School Italian Children. Nutrients 2017, 9(6).

19. Cao M, Zhu Y, He B, Yang W, Chen Y, Ma J, Jing J: Association between sleep duration and obesity is age- and gender-dependent in Chinese urban children aged 6-18 years: a cross-sectional study. BMC public health 2015, 15:1029.

20. Centers for Disease Control and Prevention. State and local youth risk behavior survey. 2017.

21. World Health Organization. Global school-based students health survey (GSHS). 2015.

22. [Body mass index reference norm for screening overweight and obesity in Chinese children and adolescents]. Zhonghua liu xing bing xue za zhi = Zhonghua liuxingbingxue zazhi 2004, 25(2):97102.

23. Paruthi S, Brooks LJ, D'Ambrosio C, Hall WA, Kotagal S, Lloyd RM, Malow BA, Maski K, Nichols C, Quan SF et al: Consensus Statement of the American Academy of Sleep Medicine on the Recommended Amount of Sleep for Healthy Children: Methodology and Discussion. Journal of clinical sleep medicine : JCSM : official publication of the American Academy of Sleep Medicine 2016, 12(11):1549-1561.

24. Tuohino T, Morales-Muñoz I, Saarenpää-Heikkilä O, Kiviruusu O, Paunio T, Hovi P, Pietiläinen KH, Paavonen EJ: Short Sleep Duration and Later Overweight in Infants. The Journal of pediatrics 2019, 212:13-19.

25. Rangan A, Zheng M, Olsen NJ, Rohde JF, Heitmann BL: Shorter sleep duration is associated with higher energy intake and an increase in BMI z-score in young children predisposed to overweight. International journal of obesity (2005) 2018, 42(1):59-64.

26. Sakamoto N, Gozal D, Smith DL, Yang L, Morimoto N, Wada H, Maruyama K, Ikeda A, Suzuki Y, Nakayama M et al: Sleep Duration, Snoring Prevalence, Obesity, and Behavioral Problems in a Large Cohort of Primary School Students in Japan. Sleep 2017, 40(3).

27. Gileles-Hillel A, Almendros I, Khalyfa A, Nigdelioglu R, Qiao Z, Hamanaka RB, Mutlu GM, Akbarpour M, Gozal D: Prolonged Exposures to Intermittent Hypoxia Promote Visceral White Adipose Tissue Inflammation in a Murine Model of Severe Sleep Apnea: Effect of Normoxic Recovery. Sleep 2017, 40(3).

28. Anderson SE, Andridge R, Whitaker RC: Bedtime in Preschool-Aged Children and Risk for Adolescent Obesity. The Journal of pediatrics 2016, 176:17-22.

29. Wang F, Liu H, Wan Y, Li J, Chen Y, Zheng J, Huang T, Li D: Sleep Duration and Overweight/Obesity in Preschool-Aged Children: A Prospective Study of up to 48,922 Children of the Jiaxing Birth Cohort. Sleep 2016, 39(11):2013-2019. 
30. Krietsch KN, Armstrong B, McCrae CS, Janicke DM: Temporal Associations Between Sleep and Physical Activity Among Overweight/Obese Youth. Journal of pediatric psychology 2016, 41(6):680691.

31. Halal CS, Matijasevich A, Howe LD, Santos IS, Barros FC, Nunes ML: Short Sleep Duration in the First Years of Life and Obesity/Overweight at Age 4 Years: A Birth Cohort Study. The Journal of pediatrics 2016, 168:99-103.e103.

32. M G: the Report on Childhood Obesity in China. Beijing: People's Medical Publishing House 2017.

33. Oellingrath IM, Hestetun I, Svendsen MV: Gender-specific association of weight perception and appearance satisfaction with slimming attempts and eating patterns in a sample of young Norwegian adolescents. Public health nutrition 2016, 19(2):265-274.

34. Spencer RA, Rehman L, Kirk SF: Understanding gender norms, nutrition, and physical activity in adolescent girls: a scoping review. The international journal of behavioral nutrition and physical activity 2015, 12:6.

35. Jean-Louis G, Williams NJ, Sarpong D, Pandey A, Youngstedt S, Zizi F, Ogedegbe G: Associations between inadequate sleep and obesity in the US adult population: analysis of the national health interview survey (1977-2009). BMC public health 2014, 14:290.

36. Fatima Y, Doi SA, Mamun AA: Longitudinal impact of sleep on overweight and obesity in children and adolescents: a systematic review and bias-adjusted meta-analysis. Obesity reviews : an official journal of the International Association for the Study of Obesity 2015, 16(2):137-149.

37. St-Onge MP, Shechter A: Sleep disturbances, body fat distribution, food intake and/or energy expenditure: pathophysiological aspects. Hormone molecular biology and clinical investigation 2014, 17(1):29-37.

38. Do YK: Causal Effect of Sleep Duration on Body Weight in Adolescents: A Population-based Study Using a Natural Experiment. Epidemiology (Cambridge, Mass) 2019, 30(6):876-884.

39. Krietsch KN, Chardon ML, Beebe DW, Janicke DM: Sleep and weight-related factors in youth: A systematic review of recent studies. Sleep medicine reviews 2019, 46:87-96.

40. Sluggett L, Wagner SL, Harris RL: Sleep Duration and Obesity in Children and Adolescents. Canadian journal of diabetes 2019, 43(2):146-152.

41. Morselli L, Leproult R, Balbo M, Spiegel K: Role of sleep duration in the regulation of glucose metabolism and appetite. Best practice \& research Clinical endocrinology \& metabolism 2010, 24(5):687-702.

42. Li L, Fu J, Yu XT, Li G, Xu L, Yin J, Cheng H, Hou D, Zhao X, Gao S et al: Sleep Duration and Cardiometabolic Risk Among Chinese School-aged Children: Do Adipokines Play a Mediating Role? Sleep 2017, 40(5):zsx042.

43. Fu J, Wang Y, Li G, Han L, Li Y, Li L, Feng D, Wu Y, Xiao X, Li M: Childhood sleep duration modifies the polygenic risk for obesity in youth through leptin pathway: the Beijing Child and Adolescent Metabolic Syndrome cohort study. 2019, 43(8):1556-1567. 
44. Schmid SM, Hallschmid M, Jauch-Chara K, Born J, Schultes B: A single night of sleep deprivation increases ghrelin levels and feelings of hunger in normal-weight healthy men. Journal of sleep research 2008, 17(3):331-334.

45. Jiang X, Hardy LL, Baur LA, Ding D, Wang L, Shi H: Sleep duration, schedule and quality among urban Chinese children and adolescents: associations with routine after-school activities. PloS one 2015, 10(1):e0115326.

46. Spiegel K, Tasali E, Penev P, Van Cauter E: Brief communication: Sleep curtailment in healthy young men is associated with decreased leptin levels, elevated ghrelin levels, and increased hunger and appetite. Annals of internal medicine 2004, 141(11):846-850.

47. Allebrandt KV, Teder-Laving M, Akyol M, Pichler I, Müller-Myhsok B, Pramstaller P, Merrow M, Meitinger T, Metspalu A, Roenneberg T: CLOCK gene variants associate with sleep duration in two independent populations. Biological psychiatry 2010, 67(11):1040-1047.

48. Mendelson M, Borowik A, Michallet AS, Perrin C, Monneret D, Faure P, Levy P, Pépin JL, Wuyam B, Flore $\mathrm{P}$ : Sleep quality, sleep duration and physical activity in obese adolescents: effects of exercise training. Pediatric obesity 2016, 11(1):26-32.

49. Albrecht U: The circadian clock, metabolism and obesity. Obesity reviews : an official journal of the International Association for the Study of Obesity 2017, 18 Suppl 1:25-33.

50. Monteleone P, Tortorella A, Docimo L, Maldonato MN, Canestrelli B, De Luca L, Maj M: Investigation of $3111 \mathrm{~T} / \mathrm{C}$ polymorphism of the CLOCK gene in obese individuals with or without binge eating disorder: association with higher body mass index. Neuroscience letters 2008, 435(1):30-33.

51. Ramos-Lopez O, Samblas M, Milagro Fl: Circadian gene methylation profiles are associated with obesity, metabolic disturbances and carbohydrate intake. 2018, 35(7):969-981.

52. Garaulet M, Lee YC, Shen J, Parnell LD, Arnett DK, Tsai MY, Lai CQ, Ordovas JM: Genetic variants in human CLOCK associate with total energy intake and cytokine sleep factors in overweight subjects (GOLDN population). European journal of human genetics : EJHG 2010, 18(3):364-369.

53. Scott EM, Carter AM, Grant PJ: Association between polymorphisms in the Clock gene, obesity and the metabolic syndrome in man. International journal of obesity (2005) 2008, 32(4):658-662.

54. Nascimento Ferreira MV, Goumidi L, Carvalho HB, De Moraes ACF, Santaliestra-Pasías AM, Kafatos A, Molnar D, Lambrinou CP, De Henauw S, Gutierrez A et al: Associations between REV-ERBa, sleep duration and body mass index in European adolescents. Sleep medicine 2018, 46:56-60.

55. Suglia SF, Kara S, Robinson WR: Sleep duration and obesity among adolescents transitioning to adulthood: do results differ by sex? The Journal of pediatrics 2014, 165(4):750-754.

56. Wang H, Hu R, Du H, Fiona B, Zhong J, Yu M: The relationship between sleep duration and obesity risk among school students: a cross-sectional study in Zhejiang, China. Nutrition \& metabolism 2018, $15: 48$.

57. Hawkins D: Reprint of: Obesity and social factors. Obesity research \& clinical practice 2016, 10(3):355-356. 
58. Bravin JI, Gutierrez AP, McCurley JL, Roesch SC, Isasi CR, Delamater AM, Perreira KM, Van Horn L, Castañeda SF, Pulgaron ER et al: Extra-familial social factors and obesity in the Hispanic Community Children's Health Study/Study of Latino Youth. Journal of behavioral medicine 2019, 42(5):947-959.

59. Mangemba NT, San Sebastian M: Societal risk factors for overweight and obesity in women in Zimbabwe: a cross-sectional study. BMC public health 2020, 20(1):103.

60. Ochoa A, Berge JM: Home Environmental Influences on Childhood Obesity in the Latino Population: A Decade Review of Literature. Journal of immigrant and minority health 2017, 19(2):430-447.

61. Miyakoshi C, Yamamoto Y, Mishina H, Shirai C, Morioka I, Fukuhara S: Childcare Environment and Japanese Children Who Are Overweight in Early Childhood. Childhood obesity (Print) 2018, 14(3):197206. 